\title{
Quantifying Redox Dynamics of $c$-Type Cytochromes in a Living Cell Suspension of Dissimilatory Metal-reducing Bacteria
}

\author{
Xiaobo Luo, ${ }^{* 1, * 2, * 4}$ Yundang WU, ${ }^{* 2}$ Tongxu LiU, ${ }^{2 \dagger}$ Fangbai LI, ${ }^{* 2}$ Xiaomin LI, ${ }^{3}$ Dandan Chen, $* 2$ \\ and Ying WANG*2 \\ *1 Guangzhou Institute of Geochemistry, Chinese Academy of Sciences, Guangzhou 510640, China \\ *2 Guangdong Institute of Eco-environmental Science \& Technology, Guangdong Key Laboratory of Integrated \\ Agro-environmental Pollution Control and Management, Guangzhou 510650, China \\ *3 The Environmental Research Institute, MOE Key Laboratory of Theoretical Chemistry of Environment, \\ South China Normal University, Guangzhou 510006, China \\ *4 University of Chinese Academy of Sciences, Beijing 100049, China
}

\begin{abstract}
To quickly and accurately quantify the redox dynamics of $c$-type cytochromes ( $c$-Cyts) in a living cell suspension, diffusetransmission UV/visible (DT-UV/Vis) and normal UV/Vis spectroscopy were used to record spectra of $c$-Cyts in living Shewanella oneidensis MR-1 bacteria. DT-UV/Vis showed a higher absorbance of $c$-Cyts and lower background compared with normal UV/Vis, because interference from cell surface scattering was removed. The extinction coefficients of oxidized $c$-Cyts $(410 \mathrm{~nm})$ and reduced $c$-Cyts $(419$ and $552 \mathrm{~nm})$ were observed. Using this method and the obtained $c$-Cyts extinction coefficients, the redox transformation kinetics of $c$-Cyts under anoxic conditions were successfully examined in the presence of various electron acceptors, including 9,10-anthraquinone-2,6-disulfonic acid, $\mathrm{Cr}$ (VI), $\mathrm{Fe}$ (III) citrate and oxygen. Therefore, the in situ spectral analysis of outer-membrane proteins of intact cells using DT-UV/Vis spectroscopy appears a promising method for investigating microbial metal reduction processes in living cell systems.
\end{abstract}

Keywords Redox dynamics, $c$-type cytochromes, intact cell, Shewanella oneidensis MR-1

(Received August 29, 2018; Accepted November 6, 2018; Advance Publication Released Online by J-STAGE November 16, 2018)

\section{Introduction}

Metal-respiring bacteria, such as Shewanella oneidensis MR-1, can reduce metals coupled with intracellular oxidation of electron donors in anoxic environments. ${ }^{1-3}$ Anaerobic respiration processes play a critical role in the biogeochemical cycles of organic and inorganic compounds. ${ }^{4-6}$ At circumneutral $\mathrm{pH}$, $\mathrm{Fe}(\mathrm{III})$ and $\mathrm{Mn}(\mathrm{IV})$ are usually present as insoluble oxide minerals that cannot pass through the outer membrane (OM) into the inside of cells and react with metal reductases located in the inner membrane or periplasm. ${ }^{7-9}$ However, cell-membrane associated $c$-Cyts in MR-1 provide a metal-reducing (Mtr) pathway that can selectively transport electrons across the OM to extracellular insoluble electron acceptors. ${ }^{10-12}$ Therefore, cellmembrane associated $c$-Cyts in MR-1 play a key role in anaerobic respiration by mediating the reduction of insoluble minerals. ${ }^{13-17}$

Recently, purified cell-membrane associated $c$-Cyts have been widely investigated in terms of their structural and functional characteristics, ${ }^{8,18,19}$ and the reaction kinetics between metals and highly purified cell-membrane associated $c$-Cyts extracted from bacteria have been studied in depth. ${ }^{20-23}$ However, a large discrepancy in redox properties has been reported between

$\dagger$ To whom correspondence should be addressed.

E-mail: txliu@ soil.gd.cn purified cell-membrane associated $c$-Cyts and those in intact cells, because the highly reactive enzymes might be readily altered during purification processes. ${ }^{24-27}$ As proteins embedded in a membrane may function together in intact cells, their properties may be influenced by a shift in the electron equilibrium. Therefore, it is essential to directly monitor cellmembrane associated $c$-Cyts in intact cells to determine the real redox status of cell-membrane associated $c$-Cyts during microbial reduction processes. ${ }^{28-30}$

Fortunately, the active center of $c$-Cyts is an iron heme complex, which has a large molar absorption coefficient. Therefore, spectroscopic methods have been used to characterize purified cell-membrane associated $c$-Cyts. ${ }^{8,19,31}$ Furthermore, $c$-Cyts located on the surface of the cell OM can also be directly measured by spectroscopic methods. ${ }^{26,28}$ Recently, $c$-Cyts in living cell suspensions have been investigated using spectroscopic methods, including evanescent wave spectroscopy and surface-enhanced infrared absorption. ${ }^{13,32,33}$ Based on the interaction between bacterial cells and electrodes, these methods can characterize redox pairs at the cell surface and monitor changes in their oxidized or reduced states during these processes. Furthermore, the cell-membrane associated $c$-Cyts content per cell can be estimated using these methods. ${ }^{32}$ Therefore, the concentration of cell-membrane associated $c$-Cyts in solution can be predicted. An in situ spectroscopic method was also used to examine the reaction between $\mathrm{Fe}^{2+}$ and $c$-Cyts in intact Leptospirillum ferrooxidans under oxic conditions. ${ }^{34}$ 
The concentration of cell-membrane associated $c$-Cyts can be accurately measured after eliminating light scattering from cell surfaces using diffuse-transmission (DT) spectroscopy. ${ }^{35-37}$ Therefore, DT-UV/Vis spectroscopy is more straightforward than other methods and seems promising for examining the redox status of cell-membrane associated $c$-Cyts in living cell suspensions. ${ }^{38,39}$ However, no comprehensive study has been conducted to determine the fundamental details of these analytical methods for in situ quantification of cell-membrane associated $c$-Cyts in a living cell suspension.

Herein, DT-UV/Vis spectroscopy was used to examine Shewanella oneidensis MR-1 as a model strain with the aim to quantify the concentrations of reduced/oxidized forms of cellmembrane associated $c$-Cyts in living MR-1 cell suspension and apply the established method to measuring the redox dynamics of $c$-Cyts in real incubation systems with various types of electron acceptors.

\section{Experimental}

\section{Materials}

Model iron-reducing bacterium Shewanella oneidensis MR-1 was purchased from the Marine Culture Collection of China (MCCC, China) and maintained in Luria-Bertani (LB) agar at $4^{\circ}$ C. 9,10-Anthraquinone-2,6-disulfonic acid (AQDS, AR) was obtained from Tokyo Chemical Industry Co., Ltd. (TCI, Japan). $\mathrm{Cr}(\mathrm{VI})$ stock solution was prepared by dissolving potassium dichromate $\left(\mathrm{K}_{2} \mathrm{Cr}_{2} \mathrm{O}_{7}, \mathrm{AR}\right.$, DAMAO, China) in water. Ferric citrate (Fe(III)-cit, AR) was purchased from Xiya Reagent (China). All other chemicals were of analytical grade and obtained from Guangzhou Chemical Co. (China). As we know, the redox center of all the different types of $c$-Cyts is a heme group. It was demonstrated that the $c$-Cyts of such diverse organisms as a mammal (bovine heart mitochondrial $c$-Cyts), photosynthetic bacteria (Rhodobacter sphaeroides c-Cyts), and soil bacteria (Paracoccus denitrificans $c$-Cyts) are not only structurally similar but also identical in terms of the microscopic electrostatics and thermodynamic properties of their key amino acids. Standard horse heart cytochrome has been used for $c$-Cyts concentration calculation in previous studies. ${ }^{40-42}$ Thus, in this study, the horse heart cytochrome $c$ was used as a model $c$-Cyts to calculate the $c$-Cyts concentration in a living cell suspension.

\section{In situ spectral measurements of c-Cyts}

The strain was inoculated and activated for $10 \mathrm{~h}$ by shaking at $180 \mathrm{rpm}$ in $\mathrm{LB}$ medium at $30^{\circ} \mathrm{C}$. The cells grown to the mid-exponential phase have high activity. In order to ensure the consistency of each experiment, the MR-1 cells in all experiments were grown to the mid-exponential phase in aerobic nutrient broth at $30^{\circ} \mathrm{C}$. Next, the suspension was centrifuged at $6000 \mathrm{~g}$ for $5 \mathrm{~min}$ at $4^{\circ} \mathrm{C}$ and the cells were washed three times with PBS buffer (pH 7.0). The washed MR-1 pellet was resuspended in PBS buffer and diluted with PBS to different desired concentrations before transferring to a quartz cuvette with an optical path length of $1.0 \mathrm{~cm}$. Spectra were collected at intervals using a UV/Vis spectrophotometer (TU-1901 Beijing, China) equipped with an IS19-1 integrating sphere reflectance attachment in the range of $300-600 \mathrm{~nm}$. For comparison, the cell suspensions were also measured using a normal UV/Vis spectrophotometer (TU-1901 Beijing, China). Schematic diagrams of spectrometers with absorption (Abs) and DT-Abs modes are shown in Figs. 1(a) and 1(b). Scattered light from the cell surfaces can be eliminated in DT-Abs mode (Fig. 1(b)) due to the integrating sphere.
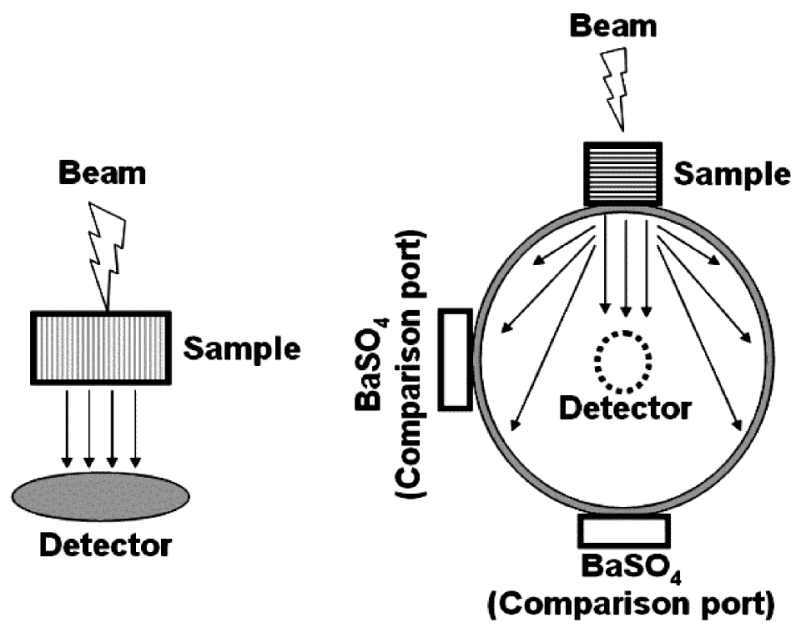

(a)

(b)

Fig. 1 Schematic diagrams of spectrometers with two different modes: (a) absorption (Abs) mode and (b) diffuse-transmittance absorption (DT-Abs) mode.

\section{Reduction experiments with various electron acceptors}

For AQDS, $\mathrm{Cr}(\mathrm{VI})$, and $\mathrm{Fe}(\mathrm{III})$ reduction experiments, the washed MR-1 pellet was transferred to an anaerobic chamber (Plas-Labs, USA, $\mathrm{H}_{2} / \mathrm{N}_{2}(2 / 98,(\mathrm{v} / \mathrm{v}))$ and resuspended in PBS buffer to a final cell density of $3.5 \times 10^{8}$ cells $\mathrm{mL}^{-1}$. The suspension was transferred to a rectangular quartz cuvette with an optical path length of $1.0 \mathrm{~cm}$ for measurement. Sodium lactate $(30 \mathrm{mM})$ was also added as an electron donor. AQDS, $\mathrm{Cr}(\mathrm{VI})$, and $\mathrm{Fe}(\mathrm{III})$ with initial concentrations of $100 \mu \mathrm{M}$ were used as electron acceptors and added in different treatments, respectively. Subsequently, the full spectrum from 300 to $600 \mathrm{~nm}$ was recorded at intervals. For oxygen $\left(\mathrm{O}_{2}\right)$ reduction experiments, the washed MR-1 pellet was resuspended in PBS buffer with a final cell density of $2.1 \times 10^{8}$ cells $\mathrm{mL}^{-1}$. Sodium lactate $(30 \mathrm{mM})$ was also added as an electron donor. To quantify the long-term kinetics of $c$-Cyts with a changing cell density, an aerobic cell suspension of MR-1 was cultured in an aerobic Erlenmeyer flask at $30^{\circ} \mathrm{C}$, and shaken continuously at $180 \mathrm{rpm}$ in $30 \mathrm{mM}$ of lactate medium. The spectrum was collected after taking the suspension from the Erlenmeyer flask. During the incubation period, a fraction of this suspension was taken out for full spectrum testing from 300 to $600 \mathrm{~nm}$ at intervals.

\section{Results and Discussion}

\section{Comparison of Abs and DT-Abs modes}

The UV/Vis absorption spectra of MR-1 cell suspensions with different concentrations are shown in Fig. 2. Both the Abs (Fig. 2(a)) and DT-Abs (Fig. 2(b)) spectra showed an intense absorption band at $410 \mathrm{~nm}$ (the Soret band), which was consistent with the in vivo heme groups of $c$-Cyts in Shewanella loihica $\mathrm{PV}-4^{43}$ and the OM decaheme $c$-Cyts purified from Shewanella oneidensis MR-1.18,24,25 With increasing cell concentration $\left(\mathrm{OD}_{600}\right)$, both the spectral baseline and the intense absorption band at $410 \mathrm{~nm}$ increased gradually. The extinction values in Abs mode were remarkably higher than those in DT-Abs mode, which was mainly attributed to the scattering 

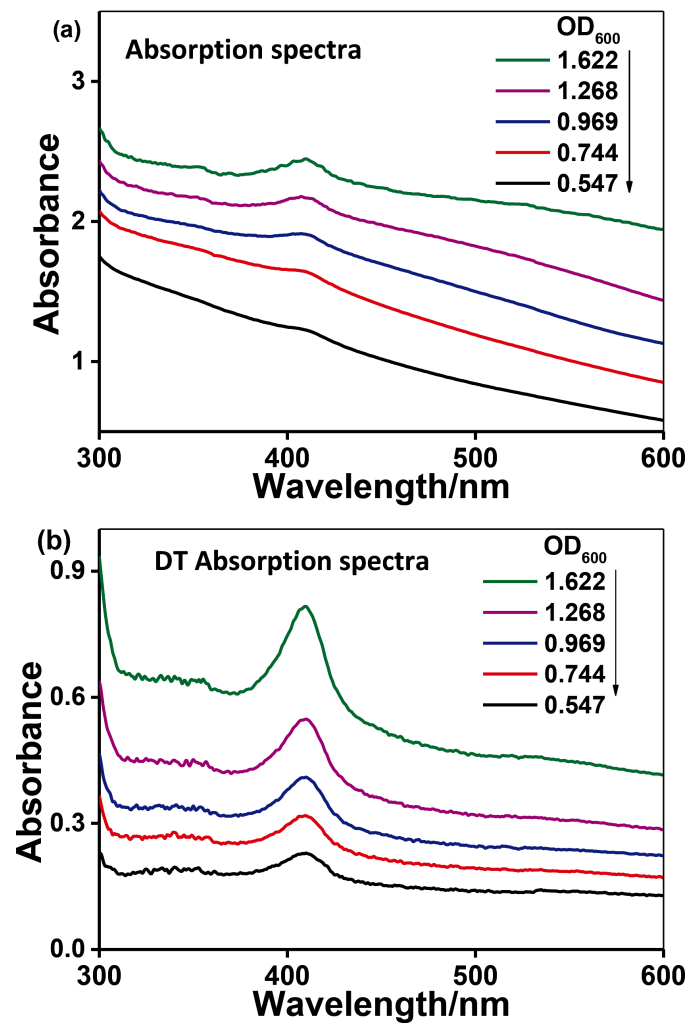

Fig. 2 UV/Vis absorption spectra of Shewanella oneidensis MR-1 cell suspensions with different concentrations $\left(\mathrm{OD}_{600}\right)$ : (a) Abs mode and (b) DT-Abs mode.

effect of the cell surfaces. ${ }^{26}$ The peak extinction values at $410 \mathrm{~nm}\left(\mathrm{EXT}_{\lambda}\right) v s . \mathrm{OD}_{600}$ are plotted in Fig. 3, with a good linear relationship obtained after fitting using Eq. (1) with correlation coefficients $(k)$ of 1.085 and 0.533 for Abs and DT-Abs modes, respectively.

$$
k=\mathrm{EXT}_{\lambda} / \mathrm{OD}_{600}
$$

Similar to the $\mathrm{OD}_{600}$ measurements, the increase in the baseline (Fig. 2) in Abs mode was thought to be attributed to the absorption and scattering of cell surfaces, while that in DT-Abs mode was only attributed to the absorption of cell surfaces. As shown in the inset of Fig. 3(a), deducting the baseline value of the peak at $410 \mathrm{~nm}$ from its extinction value gave the absorbance. When peak values vs. $\mathrm{OD}_{600}$ were plotted (Fig. 3(b)), the Abs and DT-Abs mode showed similar $k^{\prime}$ values, both of which were significantly lower than those in Fig. 3(a). Such calculations could remove the interference of absorption and scattering of the cell surfaces.

\section{Quantification of c-Cyts using DT-Abs}

Quantification of fully oxidized or fully reduced c-Cyts. Under anoxic conditions, $c$-Cyts can be reduced quickly with the oxidation of lactate by cells. However, $c$-Cyts can also be oxidized by oxygen rapidly under oxic conditions. Since it was reported that the $c$-Cyts oxidizing process is much faster than the $c$-Cyts reducing process, ${ }^{39}$ the initial $c$-Cyts was a reduced form before adding an electron donor and then quickly oxidized after adding an electron donor. Hence, the fully oxidized $c$-Cyts were obtained under the condition of $1 \mathrm{~min}$ of air purging without an electron donor, and the fully reduced $c$-Cyts were
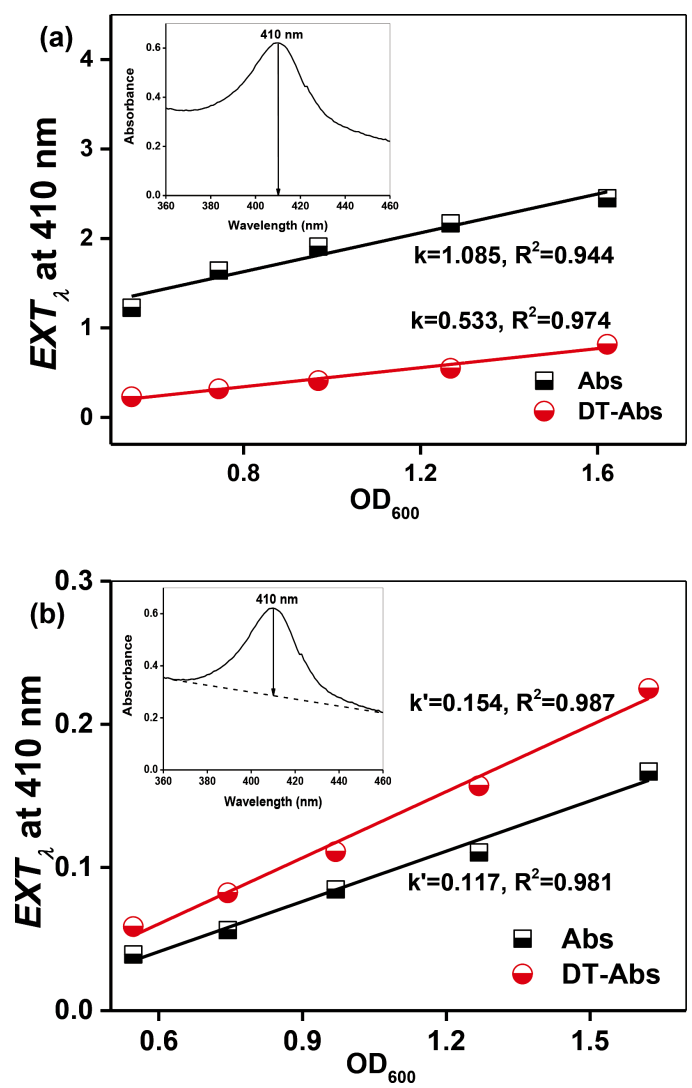

Fig. 3 (a) Fitting curves of extinction values at $410 \mathrm{~nm} v s . \mathrm{OD}_{600}$ in Abs and DT-Abs modes. (b) Fitting curves of absorbance values of the peak at $410 \mathrm{~nm} v s . \mathrm{OD}_{600}$ in Abs and DT-Abs modes.

obtained with lactate as an electron donor after 30 min of $\mathrm{N}_{2}$ purging. The spectra of both fully oxidized and fully reduced $c$-Cyts were collected for comparison. Figures 4(a) and 4(b) show the absorbance spectra of fully oxidized and fully reduced $c$-Cyts at different concentrations. For the fully oxidized $c$-Cyts, the intensity of the specific peak at $410 \mathrm{~nm}$ decreased when the stock cell suspension was diluted to different extents. For the fully reduced $c$-Cyts, the intensities of the specific peaks at 419 and $552 \mathrm{~nm}$ decreased with increasing dilution. According to the method for extracting peaks in Fig. 3(b) and the spectra in Figs. 4(a) and 4(b), calibration curves of the three peaks $(410,419$, and $552 \mathrm{~nm}$ ) were plotted, as shown in Fig. 4(c). According to the Lambert-Beer law, the extinction coefficients $\left(\varepsilon_{\lambda}\right)$ of $c$-Cyts in the cell suspensions were calculated using Eq. (2):

$$
\varepsilon_{\lambda}=2.303 \mathrm{EXT}_{\lambda} / d C
$$

where $C$ is the $c$-Cyts concentration $(\mu \mathrm{M})$ obtained from the absorbance $\left(\mathrm{EXT}_{\lambda}\right)$ and standard horse heart cytochrome; and $d$ is the optical path length of the rectangular quartz cell $(1.0 \mathrm{~cm})$. From Fig. 4(c), the extinction coefficients $\varepsilon_{410}, \varepsilon_{419}$, and $\varepsilon_{552}$ were calculated as $0.1014,0.1378$, and 0.0266 , respectively.

Redox transformation of c-Cyts with various electron acceptors. To determine the practical applicability of the DT-Abs method, the redox transformation of $c$-Cyts was examined in the presence of various electron acceptors. The bioreduction of soluble electron acceptors, including AQDS, $\mathrm{Cr}(\mathrm{VI})$, and $\mathrm{Fe}(\mathrm{III})$ citrate, was investigated, as described below. 

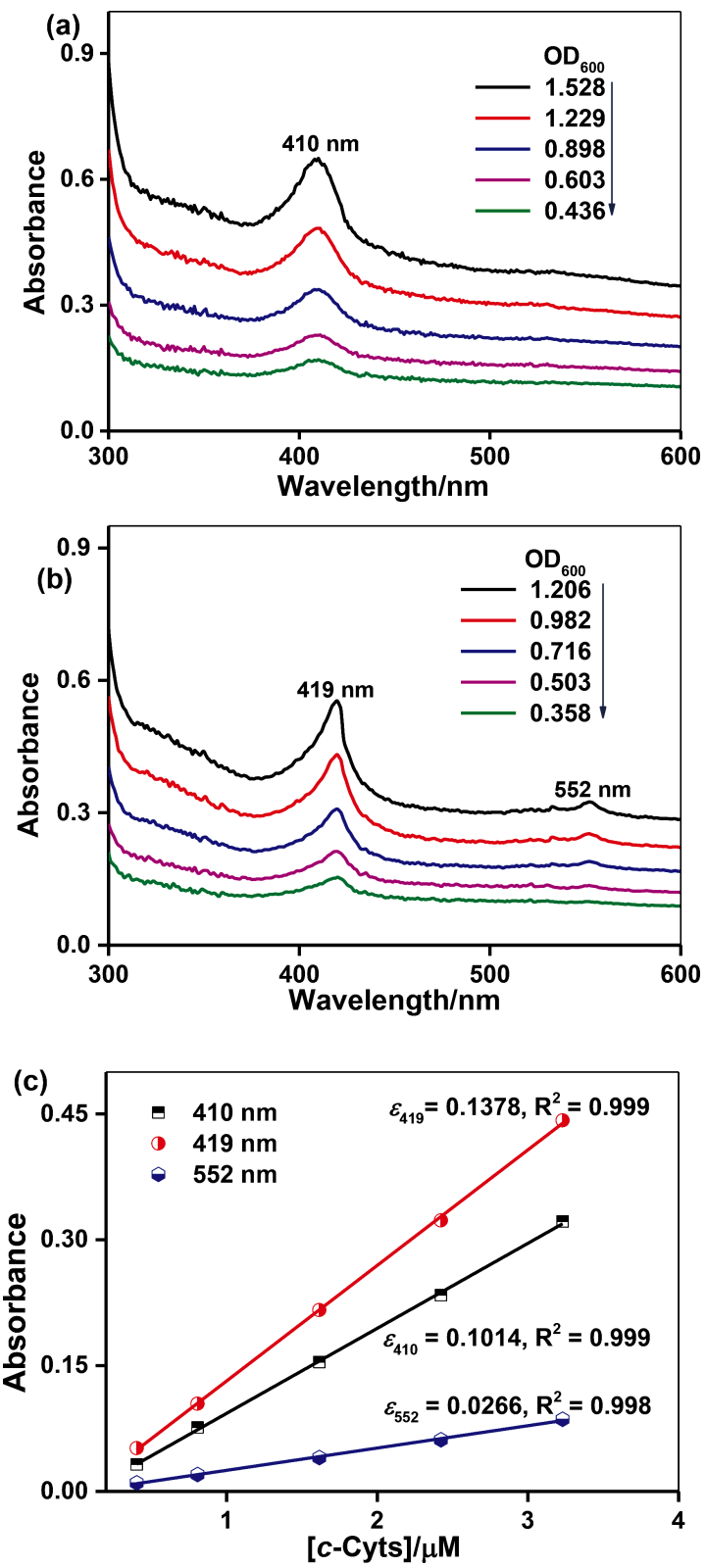

Fig. 4 DT-UV/Vis spectra of (a) fully oxidized and (b) fully reduced MR-1 cell suspensions with different concentrations. (c) Calibration curves of $c$-Cyts obtained at wavelengths of $410 \mathrm{~nm}$ (fully oxidized form) and 419/552 nm (fully reduced form).

\section{AQDS reduction}

The in situ kinetic study of AQDS reduction by $c$-Cyts in intact MR-1 cells was conducted using an initial AQDS concentration of $100 \mu \mathrm{M}$. The spectra in Fig. 5(a) clearly show that the peaks at $328 \mathrm{~nm}$ for AQDS decreased substantially over time (Fig. 5(b)). AQDS can be reduced to $\mathrm{AH}_{2} \mathrm{QDS}$ and AHQDS, which give new peaks at 385 and $408 \mathrm{~nm}$, respectively. The peak at $552 \mathrm{~nm}$ in Fig. 5(a) was attributed to $c$-Cyt $\mathrm{Ced}_{\text {red }}$ It was transiently dropped to a low level after the adding of AQDS (Fig. 5(b)). Although all the $c$-Cyt red $_{\text {was }}$ rapidly oxidized, electrons can be transferred from lactate to $c$-Cyts continuously with the microbial metabolism. So AQDS was finally reduced by the $c-\mathrm{Cyt}_{\mathrm{red}}$ with the continuous metabolism of the electron donor, and the peak at $552 \mathrm{~nm}$ finally recovered to the initial level. It is thus clear that it is feasible to simultaneously measure

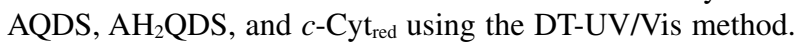
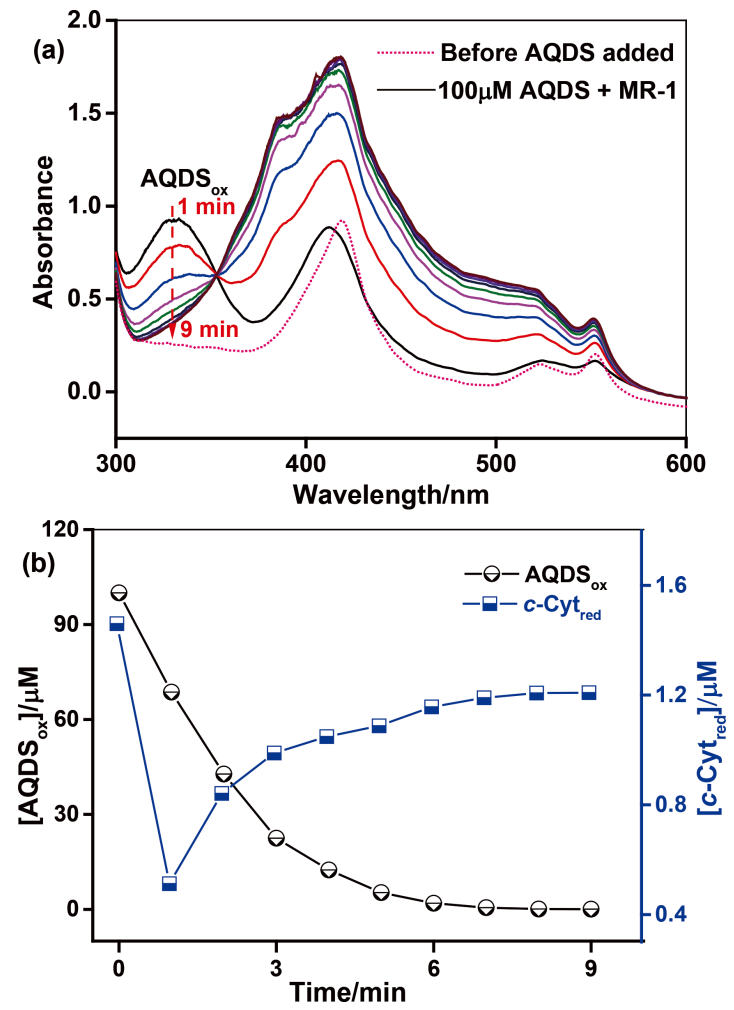

Fig. 5 AQDS reduction by $c$-Cyts in a living cell suspension of MR-1. (a) Time-resolved spectra at 9 min. Dashed line is the spectrum of MR-1 before adding AQDS. (b) Kinetics of AQDS (337 nm) and $c$-Cyt red $(552 \mathrm{~nm})$ over time. Cell density, $3.5 \times 10^{8}$ cells $\mathrm{mL}^{-1}$; initial [AQDS], $100 \mu \mathrm{M}$; [lactate], $30 \mathrm{mM}$.

\section{Cr(VI) reduction}

The in situ kinetic study of $\mathrm{Cr}(\mathrm{VI})$ reduction by $c$-Cyts in intact MR-1 cells was conducted using an initial $\mathrm{Cr}(\mathrm{VI})$ concentration of $100 \mu \mathrm{M}$. The spectra in Fig. 6(a) clearly show changes in the peaks at $373 \mathrm{~nm}$ for $\mathrm{Cr}(\mathrm{VI})$, which decreased substantially over time (Fig. 6(b)). $\mathrm{Cr}(\mathrm{VI})$ can be reduced to $\mathrm{Cr}$ (III) without producing new peaks. The peaks at $552 \mathrm{~nm}$ in Fig. 6(a) were attributed to $c$-Cyt red $_{\text {, }}$ which transiently dropped to a low level at the beginning and then gradually recovered to the initial level (Fig. 6(b)). Therefore, it is feasible to simultaneously measure $\mathrm{Cr}(\mathrm{VI})$ and $c$-Cyt $\mathrm{tred}_{\text {re }}$ using the DT-UV/ Vis method.

\section{$\mathrm{Fe}$ (III) reduction}

The in situ kinetic study of $\mathrm{Fe}(\mathrm{III})$ reduction by $c$-Cyts in intact MR-1 cells was conducted using an initial Fe(III) citrate concentration of $100 \mu \mathrm{M}$. The spectra in Fig. 7(a) show that no peak was observed for $\mathrm{Fe}(\mathrm{III})$ citrate, and only peaks for $c$-Cyt $\mathrm{Cred}_{\mathrm{r}}$ were found at $410-419$ and $552 \mathrm{~nm}$ in Fig. 7(a). The $c$-Cyt $\mathrm{red}_{\mathrm{red}}$ calculated from the peak at $552 \mathrm{~nm}$ transiently dropped to a low level at the beginning and then gradually recovered to the initial level (Fig. 7(c)). Therefore, it was feasible to measure $c$-Cyt ${ }_{\text {red }}$ using the DT-UV/Vis method. While the spectra of $c$-Cyts can be obtained directly, no typical absorbance peak for Fe(II) or $\mathrm{Fe}(\mathrm{III})$ was observed from 300 to $600 \mathrm{~nm}$. Since the 1,10-phenanthroline is a chromogenic agent for in situ measuring of $\mathrm{Fe}(\mathrm{II})$ at $510 \mathrm{~nm}$, the parallel experiments were repeated by adding 1,10-phenanthroline (Fig. 7(b)). It shows that $\mathrm{Fe}$ (II) was formed gradually, while the kinetics in Fig. 7(c) show that the $\mathrm{Fe}$ (III) citrate was reduced to $\mathrm{Fe}$ (II) gradually, accompanying the oxidation of $c-\mathrm{Cyt}_{\mathrm{red}}$. 

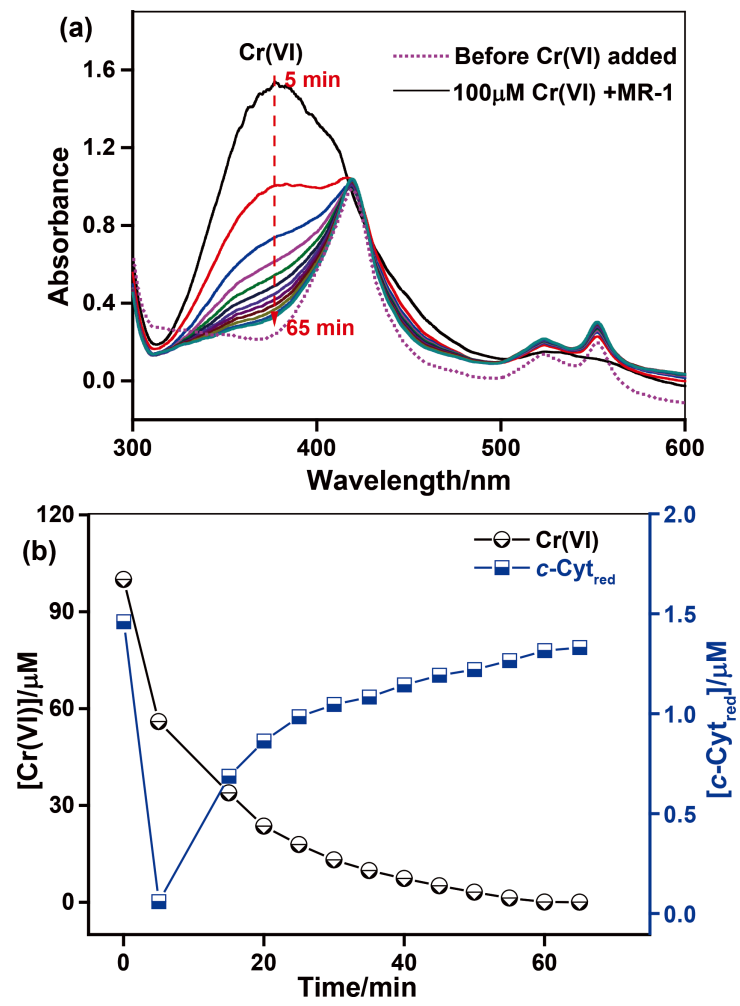

Fig. $6 \mathrm{Cr}(\mathrm{VI})$ reduction by $c$-Cyts in a living cell suspension of MR-1. (a) Time-resolved spectra at $70 \mathrm{~min}$. Dashed line is the spectrum of MR-1 before adding $\mathrm{Cr}(\mathrm{VI})$. (b) Kinetics of $\mathrm{Cr}(\mathrm{VI})$ $(372 \mathrm{~nm})$ and $c$-Cyt $\mathrm{Cred}(552 \mathrm{~nm})$ over time. Cell density, $3.5 \times 10^{8}$ cells $\mathrm{mL}^{-1}$; initial [Cr(VI)], $100 \mu \mathrm{M}$; [lactate], $30 \mathrm{mM}$.

\section{Oxygen reduction}

The above studies were conducted for short-term kinetic processes, and no obvious cell growth was observed during the short-term incubation. Therefore, the total $c$-Cyts was maintained at a stable level. However, for long-term incubation, the cell density may change substantially, with the total $c$-Cyts also changing. It was shown that the peak of $c$-Cyts stayed at $419 \mathrm{~nm}$ from 0 to $18 \mathrm{~h}$, and then it shifted from 419 to $410 \mathrm{~nm}$ from 18 to $28 \mathrm{~h}$ (Fig. 8(a)). The reduced $c$-Cyts could be generated via the oxidation of lactate by cells, while the oxidation of $c$-Cyts occurred due to the diffusion of $\mathrm{O}_{2}$. The fast decrease in $c$-Cyt $\mathrm{t}_{\text {red }}$ from 17 to $20 \mathrm{~h}$ was probably because the lactate concentration decreased substantially, and then the $c$-Cyts was transformed into oxidized form as the lactate might have been used up.

The kinetics of $c$-Cyt $\mathrm{t}_{\text {red }}$ are shown in Fig. 8(b). It shows that $c$-Cyt $_{\text {red }}$ increased gradually until $17 \mathrm{~h}$, but then decreased rapidly from 17 to $20 \mathrm{~h}$. After $20 \mathrm{~h}$, the reduced form was stable at very low levels. As the cell density might increase obviously during the long-term incubation $(28 \mathrm{~h})$, the total $c$-Cyts would also increase simultaneously. The $\mathrm{OD}_{600}$ was also monitored during incubation under oxic conditions, and the results are shown in Fig. 8(b). During incubation from 0 to $28 \mathrm{~h}$, the $\mathrm{OD}_{600}$ increased substantially from 0.68 to 1.41 . As the absorption peaks at $552 \mathrm{~nm}$ only represented the reduced form of $c$-Cyts, they were not accurate for directly quantifying the oxidized forms of $c$-Cyts. As the absorption peaks at 419 and $410 \mathrm{~nm}$ could represent the fully reduced or fully oxidized forms of $c$-Cyts, respectively, it would be feasible to quantify the oxidized forms of $c$-Cyts from these two peaks. However,
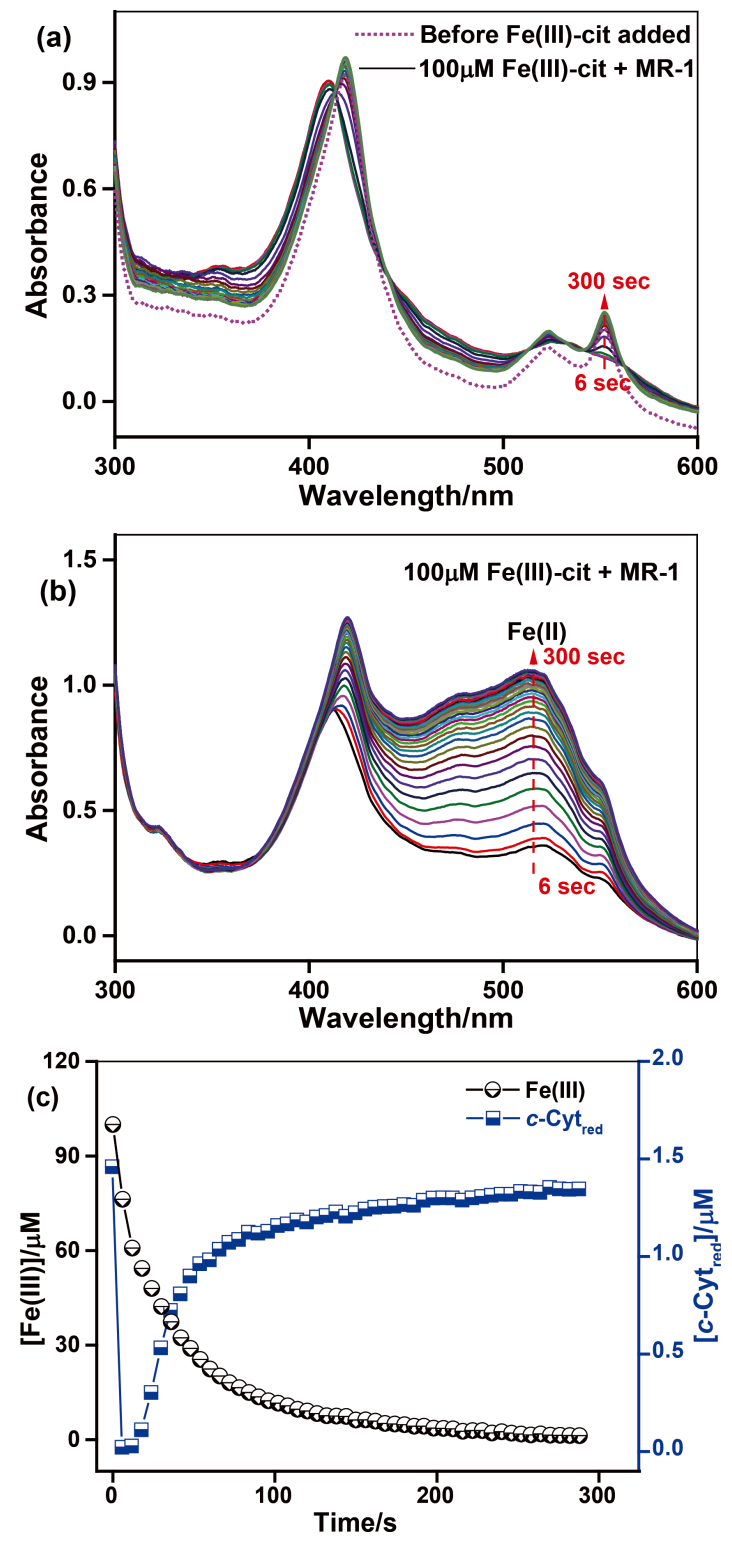

Fig. $7 \mathrm{Fe}$ (III) citrate reduction by $c$-Cyts in a living cell suspension of MR-1. (a) Time-resolved spectra at $5 \mathrm{~min}$. Dashed line is the spectrum of MR-1 before adding Fe(III). (b) Time-resolved spectra of $\mathrm{Fe}(\mathrm{III})$ citrate with 1,10-phenanthroline $(\mathrm{mM})$ at $5 \mathrm{~min}$. (c) Kinetics of $\mathrm{Fe}(\mathrm{III})$ citrate $(372 \mathrm{~nm})$ and $c$-Cyt $\mathrm{Cred}_{\text {red }}(552 \mathrm{~nm})$ over time. Cell density, $3.5 \times 10^{8}$ cells $\mathrm{mL}^{-1}$; initial [Fe-cit], $100 \mu \mathrm{M}$; [lactate], $30 \mathrm{mM}$.

the absorption peaks at 419 and $410 \mathrm{~nm}$ usually overlapped. Therefore, it is essential to establish an approach to separate the mixed spectra and calculate the $c$-Cyts concentrations of $c$-Cyt red $_{\text {red }}$ and $c$-Cyt ${ }_{\mathrm{ox}}$. As the absorbances at both 410 and $419 \mathrm{~nm}$ included the absorbances of both $c$-Cyt ${ }_{\text {ox }}$ and $c$-Cyt ${ }_{\text {red, }}$, the total absorbance of oxidized and reduced forms $\left(A_{410}\right.$ and $\left.A_{419}\right)$ can be derived using Eqs. (3) and (4) according to the Beer-Lambert law.

$$
\begin{aligned}
& A_{410}=A_{410}^{\mathrm{ox}}+A_{410}^{\mathrm{red}}=\varepsilon_{410}^{\mathrm{ox}} C_{\mathrm{ox}}+\varepsilon_{410}^{\mathrm{red}} C_{\mathrm{red}} \\
& A_{419}=A_{419}^{\mathrm{ox}}+A_{419}^{\mathrm{red}}=\varepsilon_{419}^{\mathrm{ox}} C_{\mathrm{ox}}+\varepsilon_{419}^{\mathrm{red}} C_{\mathrm{red}}
\end{aligned}
$$

where $A_{410}^{\mathrm{ox}}$ and $A_{419}^{\mathrm{ox}}$ represent the absorbances of $c$-Cyt ${ }_{\mathrm{ox}}$ at 410 and $419 \mathrm{~nm}$, and $A_{410}^{\text {red }}$ and $A_{419}^{\text {red }}$ represent the absorbances of 

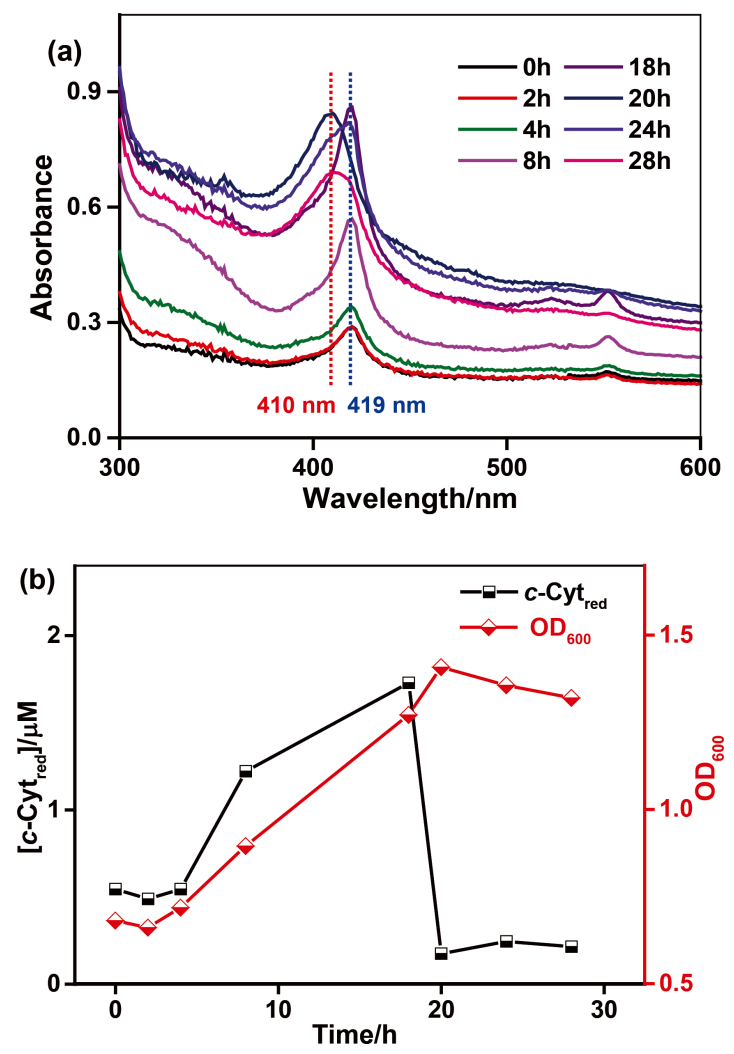

Fig. 8 Changes in cell-membrane associated $c$-Cyts in a living cell suspension of MR-1 under oxic conditions. (a) Time-resolved spectra at $28 \mathrm{~h}$. (b) Kinetics of $c$-Cyt $\mathrm{Cred}(552 \mathrm{~nm})$ and $\mathrm{OD}_{600}$ over time. Cell density, $2.1 \times 10^{8}$ cells $\mathrm{mL}^{-1}$; [lactate], $30 \mathrm{mM}$.

$c$-Cyt red $_{\text {at }} 410$ and $419 \mathrm{~nm}$, respectively. According to the above equations and the extinction coefficients of $c$-Cyt $t_{\text {red }}$ and $c$-Cyt ${ }_{o x}$ at different wavelengths (Table 1), the concentrations of both $c$-Cyt ${ }_{\text {red }}$ and $c$-Cyt ${ }_{\text {ox }}$ were calculated.

Using this method, the dynamics of the coexisting oxidized/ reduced $c$-Cyts during cultivation processes could be tracked separately. Figure 9(a) shows that $c$-Cyt red $_{\text {red }}$ had increased gradually by $17 \mathrm{~h}$, but decreased from 17 to $20 \mathrm{~h}$. After $20 \mathrm{~h}$, the reduced form was stable at very low levels. Figure 9(a) shows the results calculated from the peaks at 410 and $419 \mathrm{~nm}$, which showed a similar trend to that of the peak at $552 \mathrm{~nm}$, suggesting that these two methods were both suitable for measuring $c$-Cyt $\mathrm{t}_{\text {red. }}$. Furthermore, no obvious change in $c$-Cyt ${ }_{\text {ox }}$ was observed in the first $17 \mathrm{~h}$, followed by a rapid increase from 17 to $20 \mathrm{~h}$ and a slight decrease from 20 to $28 \mathrm{~h}$, which was attributed to the fast oxidation of $c$-Cyt $\mathrm{red}_{\text {red }}$ Based on the results in Fig. 9(a), the total $c$-Cyts was calculated from the total concentrations of $c$-Cyt ${ }_{\text {red }}$ and $c-\mathrm{Cyt}_{\mathrm{ox}}$. Figure 9(b) shows that the total $c$-Cyts had increased substantially from 1 to $3 \mu \mathrm{M}$ by $17 \mathrm{~h}$ and then decreased slightly to $2.5 \mu \mathrm{M}$ by $28 \mathrm{~h}$. The results in the inset of Fig. 9(b) show a good linear relationship between $\mathrm{OD}_{600}$ and the total $c$-Cyts concentration, suggesting that the increase in total $c$-Cyts was accompanied by an increase in cell density.

\section{Conclusions}

The results of this study suggest that, compared with normal UV/Vis spectroscopy, DT-UV/Vis spectroscopy provided higher absorbance and lower background of $c$-Cyts in living cell
Table 1 Extinction coefficients of $c$-Cyt $t_{0 x}$ and $c$-Cyt $\mathrm{r}_{\mathrm{red}}$ at different wavelengths

\begin{tabular}{|c|c|c|c|c|}
\hline \multicolumn{2}{|c|}{$c-\mathrm{Cyt}_{\mathrm{ox}} / \mu \mathrm{m} \mathrm{cm}{ }^{-1}$} & \multicolumn{3}{|c|}{$c-\mathrm{Cyt}_{\mathrm{red}} / \mu \mathrm{m} \mathrm{cm}^{-1}$} \\
\hline$\varepsilon_{410}^{\mathrm{ox}}$ & $\varepsilon_{419}^{\text {ox }}$ & $\mathcal{E}_{410}^{\mathrm{red}}$ & $\varepsilon_{419}^{\mathrm{red}}$ & $\mathcal{E}_{552}^{\mathrm{red}}$ \\
\hline 0.1014 & 0.0632 & 0.0718 & 0.1378 & 0.0266 \\
\hline
\end{tabular}
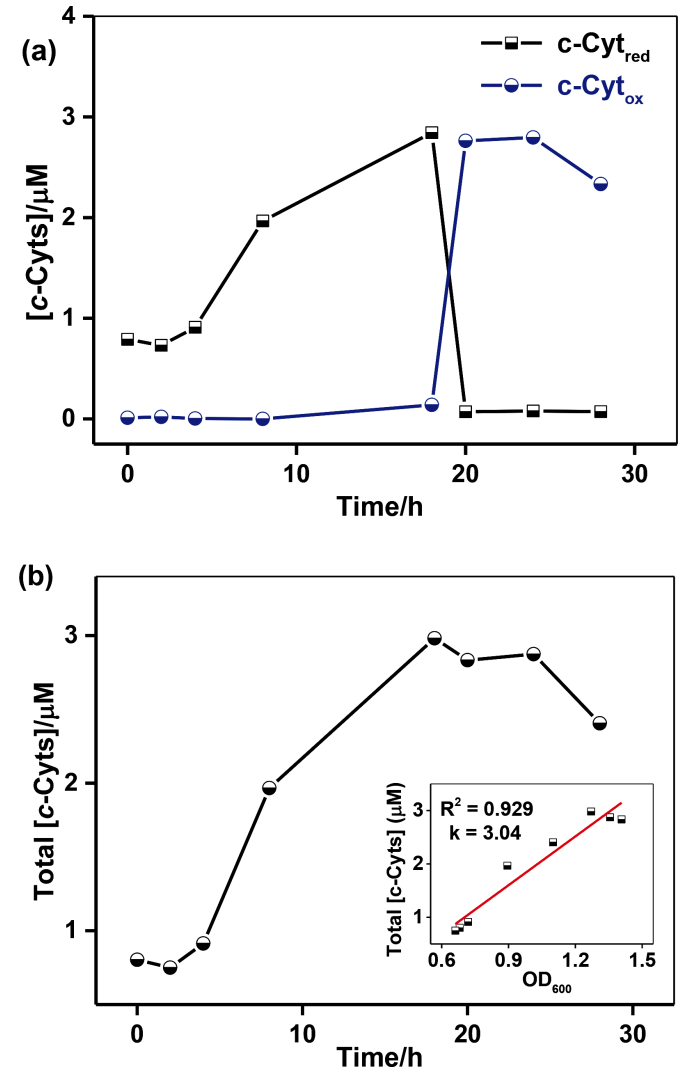

Fig. 9 (a) Kinetics of $c$-Cyt ${ }_{\text {ox }}(410 \mathrm{~nm})$ and $c$-Cyt red $_{\text {red }}(419 \mathrm{~nm})$ over time calculated from Eqs. (3) and (4). (b) Changes in total $c$-Cyts in a living cell suspension of MR-1 under oxic conditions. Inset shows the correlation of $\mathrm{OD}_{600}$ with total $c$-Cyts concentration.

suspensions. The extinction coefficients of oxidized $c$-Cyts and reduced $c$-Cyts were observed. Short-term kinetic studies demonstrated that the reduced $c$-Cyts could be accurately measured from the peak at $552 \mathrm{~nm}$, and that concentrations of AQDS and $\mathrm{Cr}(\mathrm{VI})$ could be simultaneously obtained from specific peaks, while the concentration of $\mathrm{Fe}(\mathrm{II})$ produced by Fe(III) citrate reduction could be measured in situ by adding 1,10-phenanthroline. An equation was derived to separately calculate the concentrations of pure reduced $c$-Cyts and oxidized $c$-Cyts according to the absorbance peaks at 419 and $410 \mathrm{~nm}$, respectively, while long-term kinetic studies demonstrated that the total $c$-Cyts increased linearly with cell density. This spectral approach should be a useful tool for monitoring in situ enzymatic redox reactions involved in microbial metal reduction processes in living cell systems.

\section{Acknowledgements}

This work was funded by the National Key Research and 
Development Program of China (2016YFD0800404), the National Natural Science Foundations of China (41522105), the Guangdong Natural Science Fund for Distinguished Young Scholars (2017A030306010), the Excellent Talent Fund of Guangdong Academy of Sciences (GDAS) (2017GDASCX-0408), and the SPICC (Scientific Platform and Innovation Capability Construction) program of GDAS.

\section{References}

1. C. R. Myers and K. H. Nealson, Science, 1988, 240, 1319.

2. C. Bücking, M. Schicklberger, and J. Gescher, "Microbial Metal Respirstion", 2013, Springer, Berlin Heidelberg.

3. C. R. Myers and K. H. Nealson, J. Bacteriol., 1990, 172, 6232.

4. J. M. S. Christos Gougoulias Clark and J Liz, J. Sci. Food Agric., 2014, 94, 2362.

5. D. E. Canfield, E. Kristensen, and T. Bo, Adv. Mar. Biol., 2005, 48, 269.

6. K. A. Weber, L. A. Achenbach, and J. D. Coates, Nat. Rev. Microbiol., 2006, 4, 752.

7. L. Shi, K. M. Rosso, T. A. Clarke, D. J. Richardson, J. M. Zachara, and J. K. Fredrickson, Front. Microbiol., 2012, 3, 50.

8. K. E. Pitts, P. S. Dobbin, F. Reyes-Ramirez, A. J. Thomson, D. J. Richardson, and H. E. Seward, J. Biol. Chem., 2003, 278, 27758.

9. M. N. Alves, S. E. Neto, A. S. Alves, B. M. Fonseca, A. Carrêlo, I. Pacheco, C. M. Paquete, C. M. Soares, and R. O. Louro, Front. Microbiol., 2015, 6, 665.

10. G. F. White, Z. Shi, L. Shi, Z. Wang, A. C. Dohnalkova, M. J. Marshall, J. K. Fredrickson, J. M. Zachara, J. N. Butt, and D. J. Richardson, Proc. Natl. Acad. Sci. U. S. A., 2013, 110, 6346.

11. K. Ishiki, K. Okada, L. E. Dq, H. Shiigi, and T. Nagaoka, Anal. Sci., 2017, 33, 129.

12. K. Ishiki, H. Shiigi, and T. Nagaoka, Anal. Sci., 2017, 33, 551.

13. D. Coursolle, D. B. Baron, D. R. Bond, and J. A. Gralnick, J. Bacteriol., 2010, 192, 467.

14. S. Liang, T. C. Squier, J. M. Zachara, and J. K. Fredrickson, Mol. Microbiol., 2007, 65, 12.

15. M. Breuer, K. M. Rosso, J. Blumberger, and J. N. Butt, J. R. Soc., Interface, 2014, 12, 20141117.

16. C. Dan and J. A. Gralnick, Mol. Microbiol., 2010, 77, 995.

17. S. Liang, D. J. Richardson, Z. Wang, S. N. Kerisit, K. M. Rosso, J. M. Zachara, and J. K. Fredrickson, Environ. Microbiol. Rep., 2009, 1, 220.

18. R. S. Hartshorne, B. N. Jepson, T. A. Clarke, S. J. Field, J. Fredrickson, J. Zachara, S. Liang, J. N. Butt, and D. J. Richardson, JBIC, J. Biol. Inorg. Chem., 2007, 12, 1083.

19. T. A. Clarke, M. J. Edwards, A. J. Gates, H. Andrea, G. F. White, B. Justin, C. L. Reardon, S. Liang, A. S. Beliaev, and M. J. Marshall, Proc. Natl. Acad. Sci. U. S. A., 2011, $108,9384$.

20. E. V. Ainsworth, C. W. Lockwood, G. F. White, E. T.
Hwang, T. Sakai, M. A. Gross, D. J. Richardson, T. A. Clarke, L. J. Jeuken, and E. Reisner, Chembiochem, 2016, 17, 2324.

21. J. Liu, C. I. Pearce, L. Shi, Z. Wang, Z. Shi, E. Arenholz, and K. M. Rosso, Geochim. Cosmochim. Acta, 2016, 193, 160.

22. A. Sheng, F. Liu, L. Shi, and J. Liu, Environ. Sci. Technol., 2016, 50, 11016.

23. T. Fukushima, S. Gupta, B. Rad, J. A. Cornejo, C. J. Petzold, L. Chan, R. A. Mizrahi, C. Y. Ralston, and C. M. Ajofranklin, J. Am. Chem. Soc., 2017, 139, 12647.

24. D. E. Ross, S. L. Brantley, and M. Tien, Appl. Environ. Microbiol., 2009, 75, 1157.

25. C. L. Reardon, A. C. Dohnalkova, P. Nachimuthu, D. W. Kennedy, D. A. Saffarini, B. W. Arey, L. Shi, Z. Wang, D. Moore, J. S. Mclean, D. Moyles, M. J. Marshall, J. M. Zachara, J. K. Fredrickson, and A. S. Beliaev, Geobiology, 2010, 8, 56.

26. R. Nakamura, K. Ishiii, and K. Hashimoto, Angew. Chem., Int. Ed., 2009, 121, 1634.

27. G. F. White, Z. Shi, L. Shi, A. C. Dohnalkova, J. K. Fredrickson, J. M. Zachara, J. N. Butt, D. J. Richardson, and T. A. Clarke, Biochem. Soc. Trans., 2012, 40, 1257.

28. R. Han, F. Li, T. Liu, X. Li, Y. Wu, Y. Wang, and D. Chen, Front. Microbiol., 2016, 7, 746.

29. Y. Wu, F. Li, T. Liu, R. Han, and X. Luo, Electrochim. Acta, 2016, 213, 408.

30. R. Han, X. Li, Y. Wu, F. Li, and T. Liu, Colloids Surf., A, 2017, 520, 505.

31. R. S. Hartshorne, C. L. Reardon, D. Ross, J. Nuester, T. A. Clarke, A. J. Gates, P. C. Mills, J. K. Fredrickson, J. M. Zachara, and L. Shi, Proc. Natl. Acad. Sci. U. S. A., 2009 , 106, 22169.

32. A. Okamoto, Y. Tokunou, and J. Saito, Biophys. Physicobiol., 2016, 13, 71.

33. J. P. Busalmen, A. Berná, and J. M. Feliu, Angew. Chem., 2008, 47, 4874.

34. R. C. B. Ii and M. N. Griff, Front. Microbiol., 2012, 3, 136.

35. T. Liu, X. Li, W. Zhang, M. Hu, and F. Li, J. Colloid Interface Sci., 2014, 423, 25.

36. W. Zhang, X. Li, T. Liu, F. Li, and W. Shen, Colloids Surf., A, 2014, 445, 97.

37. Y. Wu, T. Liu, X. Li, and F. Li, Environ. Sci. Technol. 2014, 48, 9306.

38. T. Liu, X. Li, F. Li, H. Rui, Y. Wu, Y. Xiu, and W. Ying, Sci. Rep., 2016, 6, 29592.

39. T. Liu, Y. Wu, F. Li, X. Li, and X. Luo, ChemistrySelect, 2017, 2, 1008.

40. F. W. Picardal, R. G. Arnold, H. Couch, A. M. Little, and M. E. Smith, Appl. Environ. Microbiol., 1993, 59, 3763.

41. D. M. Popovic, I. V. Leontyev, D. G. Beech, and A. A. Stuchebrukhov, Proteins, 2010, 78, 2691.

42. T. Liu, Y. Wang, X. Li, and F. Li, Chem. Geol., 2017, 468, 97.

43. A. Okamoto, R. Nakamura, K. Ishii, and K. Hashimoto, Chembiochem., 2009, 10, 2329. 